doso en la 1

ar ejemplos a

is funcionalidac uso, dependiende encarnan los conceptos detr por e $\Lambda$ influ
$\mathrm{Pe}$ infin:

Las formas $d r$ oceso de sig ialidad .

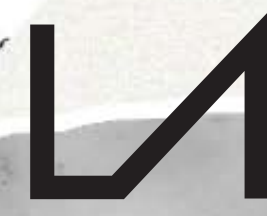

R E V I S A
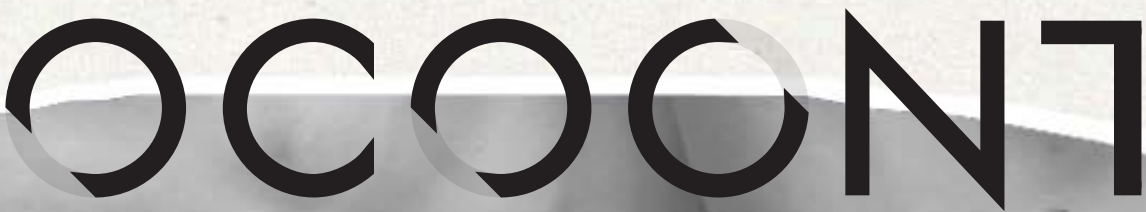

D $E$

No $6 \cdot 2019 \cdot$ ISSN 2386-8449

"El producto del diseñador es un proyecto, el estado previo de un objeto", Entrevista con Norberto Chaves, por Fernando Infante

El papel de la investigación y la teoría en diseño. Una conversación abierta, por Fernando Infante y María Jesús Godoy

UT PICTURA POESIS

Abandonar la escritura. Poesía experimental y manifiesta, Ignacio Gómez de Liaño

PANORAMA: FILOSOFÍA DEL DISEÑO Sección coordinada por Fernando Infante y María Jesús Godoy

Pensar el diseño, Fernando Infante y María Jesús Godoy (Coordinadores)

TEXTOS INVITADOS

Estatus y estado del điseño más allá del objeto, Pedro Medina Reinón

Mar de Nubes, Cuerpo de Cristal, Dionisio González

ARTÍCULOS

Understanding Design Aesthetics beyond Functional Beauty accounts, Lucía Jiménez Sánchez

Estética y diseño industrial: debates y controversias, Joan M. Marín

Del ornamento al delito. El diseño y la sociedad en Charles Baudelaire y Adolf Loos, Jorge López Lloret

When is Architecture not Design? Saul Fisher

Diseño y habitabilidad: una aproximación basada en los lenguajes de patrones, Antonio Hidalgo Pérez

Marcel Breuer: un diseñador global. Experiencias en el ámbito de la vivienda prefabricada, Salvador J. Sanchis, Ignacio Peris y Pedro Ponce Diseño y artes escénicas: el papel de Oskar Schlemmer en Das Triadische Ballett y la actualidad de la Bauhaus, Milagros García Vázquez Lo performativo en prácticas de arte y diseño actuales vinculadas a procesos de innovación social. El caso de La Venezia che non si vede y de La borda, Tània Costa Gomez

Articulaciones de la estética y el diseño. El caso de la evaluación a partir de la investigación dirigida en la carrera de diseño escénico de la Universidad de las Artes de Cuba, Mara Rodríguez Venegas y Xiomara Romero Rojas

SUPLEMENTO

El diseño, la ciudad y un lápiz de labios, Mercedes Espiau, Mar García Ranedo y Alejandro Rojas mas. 


\section{UつCつCNTE}

No $6 \cdot 2019 \cdot \operatorname{ISSN} 2386-8449 \cdot$ DOI 10.7203/LAOCOONTE.5.15381

https://ojs.uv.es/index.php/LAOCOONTE/index

COORDINACIÓN EDITORIAL

Anacleto Ferrer (Universitat de València)

Francesc Jesús Hernàndez i Dobon (Universitat de València)

Fernando Infante del Rosal (Universidad de Sevilla)

SECRETARÍA DE REDACCIÓN

Lurdes Valls Crespo (Universitat de València)

Vanessa Vidal Mayor (Universitat de València)

COMITÉ DE REDACCIÓN

Tamara Djermanović (Universitat Pompeu Fabra), Rosa Fernández Gómez (Universidad de Málaga), Anacleto Ferrer (Universitat de València), Ilia Galán (Universidad Carlos III), Ana María García Varas (Universidad de Zaragoza), María Jesús Godoy (Universidad de Sevilla), Fernando Infante del Rosal (Universidad de Sevilla), Miguel Ángel Rivero (Universidad de Sevilla), Miguel Salmerón (Universidad Autónoma de Madrid), Gerard Vilar (Universitat Autònoma de Barcelona).

COMITÉ CIENTÍFICO INTERNACIONAL

Rafael Argullol* (Universitat Pompeu Fabra), Luis Camnitzer (State University of New York), José Bragança de Miranda (Universidade Nova de Lisboa), Bruno Corà (Università di Cassino), Román de la Calle* (Universitat de València), Eberhard Geisler (Johannes Gutenberg-Universität Mainz), José Jiménez* (Universidad Autónoma de Madrid), Jacinto Lageira (Université Paris 1 Panthéon-Sorbonne), Bernard Marcadé (École Nationale Supérieure d'Arts de Paris-Cergy), Elena Oliveras (Universidad de Buenos Aires y Universidad del Salvador), Pablo Oyarzun (Universidad de Chile), Francisca Pérez Carreño* (Universidad de Murcia), Bernardo Pinto de Almeida (Faculdade de Belas Artes da Universidade do Porto), Luigi Russo (Università di Palermo), Georges Sebbag (Doctor en Filosofía e historiador del surrealismo), Zoltán Somhegyi (University of Sharjah, United Arab Emirates), Robert Wilkinson (Open University-Scotland), Martín Zubiria (Universidad Nacional de Cuyo). *Miembros de la Sociedad Española de Estética y Teoría de las Artes, SEyTA

\begin{tabular}{lll}
\hline DIRECCIÓN DE ARTE & REVISIÓN DE TEXTOS & TRANSCRIPCIÓN DE TEXTOS \\
El golpe. Cultura del entorno & Antonio Cuesta & Álvaro G. Serna
\end{tabular}

(cc) BY Excepto que se establezca de otra forma, el contenido de esta revista cuenta con una licencia Creative Commons Atribución 3.0 España, que puede consultarse en http://creativecommons.org/licenses/by/3.0/es/deed.es

EDITA

\section{SEyTA.}

CON LA COLABORACIÓN DE

\begin{tabular}{|c|c|c|c|}
\hline $\begin{array}{l}\text { VNIVERSITAT } \\
\text { ID VALENCIA } \\
\text { Institut a Creativitat } \\
\text { i|nnovacions Educatives }\end{array}$ & $\begin{array}{l}\text { VNIVERSITAT } \\
\text { IE ÖVALENCIA Departament de Filosofia }\end{array}$ & 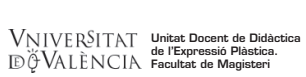 & \\
\hline $\begin{array}{l}\text { DEPARTAMENTO DE ESTÉTICA } \\
\text { E HISTORIA DE LA FILOSOFIA }\end{array}$ & $\frac{\text { UAW }}{\frac{\text { UNIVERSIDAD AUTONOMA }}{\text { DE MADRID }}}$ & $\begin{array}{l}\text { AB } \\
\text { Universitat Autònoma } \\
\text { de Barcelona }\end{array}$ & 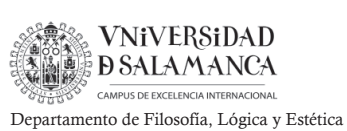 \\
\hline
\end{tabular}

LAOCOONTE aparece en los catálogos: 


\section{LつCつCN7E}

"Cuanto más penetramos en una obra de arte más pensamientos suscita ella en nosotros, y cuantos más pensamientos suscite tanto más debemos creer que estamos penetrando en ella".

G. E. Lessing, Laocoonte o los límites entre la pintura y la poesía, 1766.

Vo hay cól.

létodo, de pen.

:ión en general. Ith

zar la forma para el $\mathrm{n}$.

eptual por las orígenes

la, el objeto, la exposición

storia, porque existe en el $\mathrm{m}$

das sus raíces. Desde alli cc _. panoram

n conceptual y donde el émencia del con 'iseñado, como es el a al objeto y el di $\begin{array}{ll}\text { igen } \mathrm{de}^{\text {to }} \text { la inmer } & \text { tolvidada, o comc } \\ \text { trozo de madera ar }\end{array}$ a manera dorm comunicar ene nundo. Seguin? sngo en manos te el método $C$ les. A partir c teria prima $\mathrm{p}_{\mathbf{c}}$

'xto se puede:

¿ño, en proyea

amientos de $\mathrm{u}$

a conscie-

.)

en la publicación jue "plos de la impor te las nalidades porqu ura un ${ }^{2}$ diendo de qui zenerar $\mathrm{u}$ ción de nr? lne

in-

n-

is.

le http:,

le crear visualidades. A partir de.

ellas la propia materia prima para un en que desde un texto se puede generar $u_{11}$ i

Pensar en diseño, en proyección de nue

posibles comportamientos de una colecti

presente como una consciencia del hecho que estamos elaborando, significac

nuestro entorno (..)

Cardoso, R. C. Rafael. (2014). Design para um mundo complexo. Sãc asil: Cosac Naify. 


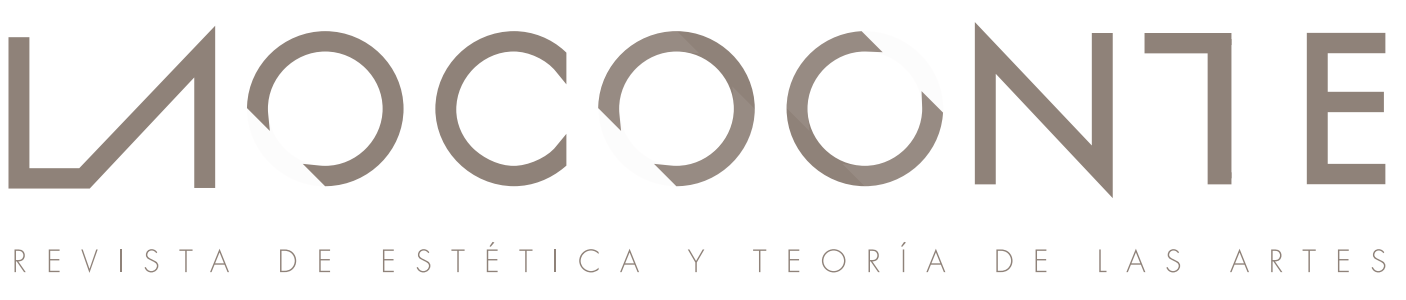

$\mathrm{N}^{\circ} 6 \cdot 2019$

PRESENTACIÓN

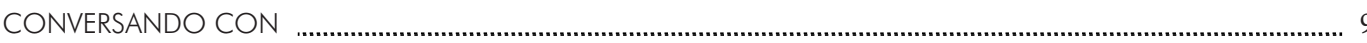

"El producto del diseñador es un proyecto, el estado previo de un objeto", Entrevista con Norberto Chaves,

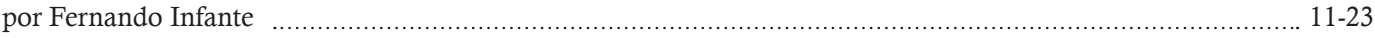

El papel de la investigación y la teoría en diseño. Una conversación abierta, por Fernando Infante

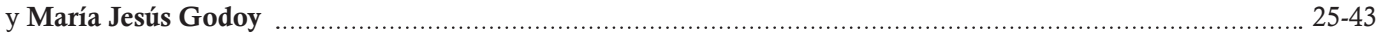

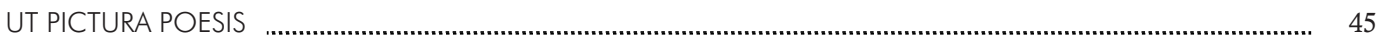

Abandonar la escritura. Poesía experimental y manifiesta, Ignacio Gómez de Liaño ................................................ 47-95

Imágenes de Laocoonte n. 6, de Isadora Gonzaga ................................................................................................... 96-97

PANORAMA

FILOSOFÍA DEL DISEÑO

Pensar el diseño, Fernando Infante y María Jesús Godoy (Coordinadores) .............................................. 101-105

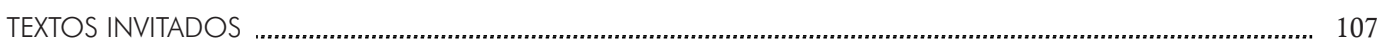

Estatus y estado del diseño más allá del objeto, Pedro Medina Reinón . ................................................... 109-125

Mar de Nubes. Cuerpo de Cristal, Dionisio González .............................................................................. 127-133

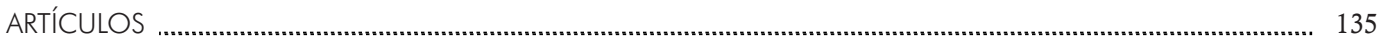

Understanding Design Aesthetics beyond Functional Beauty accounts, Lucía Jiménez Sánchez ................. 137-149

Estética y diseño industrial: debates y controversias, Joan M. Marín _...................................................... 150-164

Del ornamento al delito. El diseño y la sociedad en Charles Baudelaire y Adolf Loos, Jorge López Lloret ... $165-182$

When is Architecture not Design? Saul Fisher ……............................................................................. 183-198

Diseño y habitabilidad: una aproximación basada en los lenguajes de patrones, Antonio Hidalgo Pérez ...... 199-215

Marcel Breuer: un diseñador global. Experiencias en el ámbito de la vivienda prefabricada,

Salvador José Sanchis, Ignacio Peris y Pedro Ponce

Diseño y artes escénicas: el papel de Oskar Schlemmer en Das Triadische Ballett y la actualidad de la Bauhaus, Milagros García Vázquez

Lo performativo en prácticas de arte y diseño actuales vinculadas a procesos de innovación social.

El caso de La Venezia che non si vede y de La borda, Tània Costa Gomez

Articulaciones de la estética y el diseño. El caso de la evaluación a partir de la investigación dirigida en la carrera de diseño escénico de la Universidad de las Artes de Cuba, Mara Rodríguez Venegas

y Xiomara Romero Rojas

SUPLEMENTO 
Walter Gropius. La vida del fundador de la Bauhaus, Jorge Martínez Alcaide

¿Qué significa pensar la política desde la estética? Àger Pérez Casanovas

Ideologías estéticas en los orígenes de la pintura moderna, José Luis Plaza Chillón 300-303

Sobre a estética, Luis Carlos Pereira

Músicas populares. Sociedad y territorio: Sinergias entre investigación y docencia, Mar Aleixandre Badenes.

307-309

La necesidad de la mirada antropológica sobre la literatura, Pablo de Benito David

A propósito de Chandler, o la novela policíaca como tratado filosófico, Juan Evaristo Valls Boix

Videre aude!, Anacleto Ferrer

La inaplazable memoria del dolor y el sufrimiento, Antonio Notario Ruiz

La alargada sombra de la pintura, Raquel Baixauli

Sondear la maravilla, Juan Evaristo Valls Boix

... Y lo sabes, Marc Hernández Montoro

Arqueologías de la modernidad en las artes. Ensayo estético, Carlota Fernández-Jáuregui Rojas

Estética de la Instalación, Luis Cemillán Casis

La Herencia de otra época, María Jesús Godoy Domínguez

Del Theatrum Mundi al Gran Vidrio, Miguel Salmerón Infante

Imágenes de Isadora Gonzaga.

Fotografía de portada de Tamara Djermanovic intervenida por Isadora Gonzaga.

Los coordinadores de la sección Panorama: Filosofia del diseño agradecen

a Antonio Molina Flores su colaboración. 


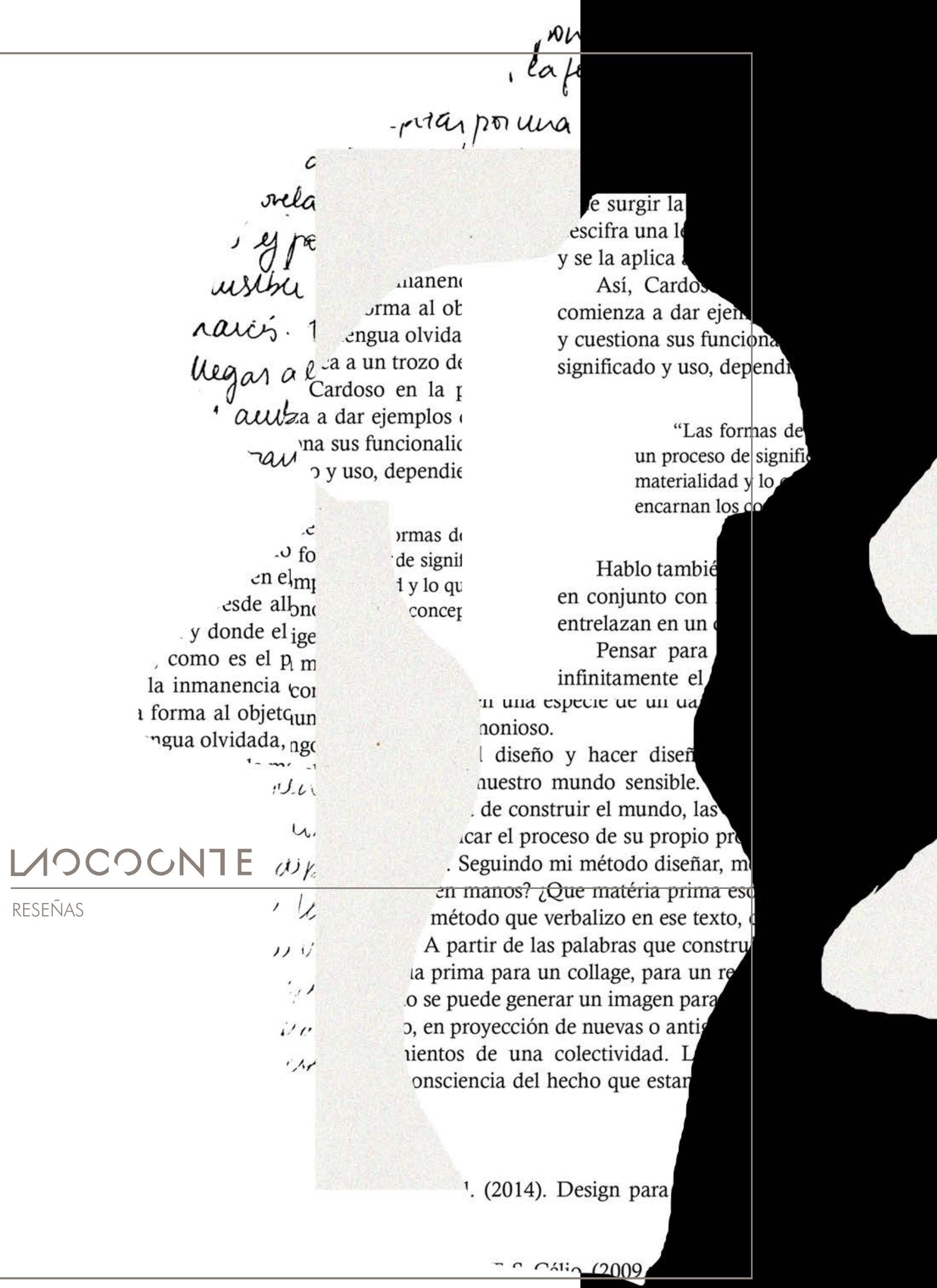




\title{
La necesidad de la mirada antropológica sobre la literatura
}

\author{
Pablo de Benito David*
}

\begin{tabular}{|c|c|}
\hline 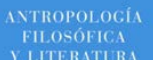 & Joan B. Llinares (ed.) \\
\hline YLITERATLRA & Antropología filosófica y literatura \\
\hline & PRE-TEXTOS, Valencia, 2019 \\
\hline & ISBN: 978-84-178307-3-1 \\
\hline & Páginas: 424 \\
\hline
\end{tabular}

Nos parece obligatorio empezar diciendo lo que este libro representa: un homenaje. Con su genuina y activa personalidad y su más que demostrada sabiduría, el profesor Joan B. Llinares edita un nuevo libro configurado desde un prisma completamente heterogéneo de saberes que cristalizan en su pasión y su disciplina. Este proyecto no podía haber llegado a realizarse sin la Unidad Docente de Metafísica y Teoría del Conocimiento integrada en el Departamento de Filosofía de la Universitat de València, que celebra así la jubilación de un compañero irrepetible.

De la mano de nada menos que trece antiguos alumnos, Antropología filosófica y literatura es un libro consagrado a revisar las líneas del pensamiento cultural histórico desde las ópticas modernas hasta las más contemporáneas. Marco Polo, Goethe, F. Dostoievski, Walter Benjamin, Cormac McCarthy, Jorge Semprún o G. Deleuze son algunos de los autores que aparecen para ser reflexionados, pensados y estudiados desde una nueva mirada comparativa. En su haber, el logro de una edición cuidada al milímetro, revisada y acondicionada para el lector que sabe apreciar el gusto por la decisión, la resolución y el trabajo bien hecho. Como todo buen homenaje, y esto se nota en los artículos que conforman el libro, se ha construido desde el apego, la admiración y, con una fuerte dosis de respeto, desde la influencia de un mirar característico, antropológico, literario: filosófico, en definitiva. Las huellas de ese estilo filosófico aprendido se ven, se leen y, lo más importante, se sienten.

El apoyo material que tiene la filosofía en la literatura nunca fue sutil, sino que más bien para muchos ha sido evidente, intuitivo y elemental. La literatura guarda en su simiente el transmitir del mensaje filosófico, manifiesto para el ojo estudioso y la mente exegética. La antropología, por su parte, representa esa nueva mirada que se fija en los detalles que se pasaron por alto, que importaban sólo por su aportación descriptiva o argumental. La antropología encuentra en la literatura una fotografía nítida de un tiempo pretérito, un campo fértil donde entrever los pensamientos de los antiguos y los modernos; encuentra las formas de discernir de los hombres y mujeres que nos precedieron. Por ello, antropología, filosofía y literatura van, si no unidas, entrelazadas como galaxias cercanas por la fuerza y la determinación de la constelación de la

* Universitat de València, España. pablo.beda@gmail.com 
creación humana.

La obra consta de catorce artículos que tratan unas temáticas muy diversas que hacen imposible una síntesis comunitaria. Sin embargo, el rasgo característico de todas ellas es su punto de partida y su destino: la literatura y la antropología filosófica. Todos los textos excavan en la tradición literaria para conformar un discurso histórico y antropológico que sintetiza, examina e interpreta su marco cultural y su preocupación filosófica.

El primero de ellos, elaborado por Bernat Martí Oroval nos introduce en la fascinante visión del Occidente tardo-medieval y renacentista sobre Oriente, concretamente Japón. "Del Cipango de Marco Polo al Japón de Francisco Javier" es una muestra evidente de que las ideas mueven a los hombres a explorar los lugares más allá de la imaginación. Para los europeos, aquellas tierras eran el lugar del éxito y del fracaso absoluto: "[...] se hablaba de la existencia de seres fantásticos, monstruos, [e] inmensas minas de oro [...]" (p.31). De la aventura a la "antropología misional" de Francisco Javier podría pensarse que esta idea se transformó, pero Bernat Martí Oroval muestra cómo lo mítico, inscrito en la propia narración de las experiencias de "los otros", de alguna forma, jamás abandonó los relatos.

El análisis de Kilian Lavernia narra el significado de la derrota bélica en dos obras -consideradas menores- del gran poeta alemán Goethe. Muestra cómo Goethe articula una "comprensión de la historia a partir de la naturaleza, y no una comprensión del mundo a partir de la historia" (56) con dimensiones antropológicas fundamentales para la interpretación epistémica del "yo" como una permanente lucha contra sí mismo. Kilian Lavernia en, "Por ejemplo, Goethe en la guerra. Antropología de la existencia", evidencia el trasfondo del estilo goethiano: no hay que maquillar la realidad, sino lo contrario: la narración de la guerra debe ser igual de dura en términos estéticos.

Luca Giancristofaro estudia en su ensayo dedicado a la imaginación poética diltheyana la poderosa influencia que ejerció el poeta Goethe en la producción del filósofo alemán. Nuestro autor comenta y expone el carácter positivista de Dilthey en su intento por crear una teoría psicológica de la poesía basada en la constitución psico-fisiológica del artista, evidenciando la poderosa y estrecha relación que une la literatura a la antropología filosófica. Dilthey enmarca como elemento fundacional para el análisis estético la fantasía creadora y la hermenéutica, analizando "[...] la relación entre la fantasía poética y la realidad vivida por el poeta, la experiencia vital” (88).

Lorena Rivera nos ofrece una lectura propia del conflicto que vertebra la obra de Dostoievski -razón contra fe- en la obra Los demonios. La interpretación, apoyada en obras fundamentales como Apuntes del subsuelo y El sueño de un hombre ridículo, construye un relato antropológico que encuentra, expone y analiza la fuerza y la reverberación de los cismas internos más fundamentales del carácter humano en la literatura, mostrando, además, su enorme repercusión y eco en la propia antropología filosófica. De este modo, ofrece una visión altamente especializada centrándose en el estudio sistemático de los personajes clave de las diferentes obras del clásico ruso y sus coetáneos.

Pedro Piedras nos expone la innegable contemporaneidad de la sensibilidad de Hugo von Hofmannsthal por el dolor animal -como sufrimiento provocado por el arbitrio del comportamiento humano- que se muestra en sus relatos. La ingenuidad, su perfección moral y su fidelidad -entre otros elementos- otorgan a los animales, según Pedro Piedras, una dignidad sobrehumana que serviría a Hofmannsthal para mostrar "[...] lo despiadado del ser humano de un modo diferido pero igualmente 
salvaje" (163) y que, por supuesto, quedaba exento de la ley y de su castigo. Su carácter antropológico es esencial: nuestra violencia sobre ellos no nos habla de ellos, sino de nosotros. Por otra parte, Pedro Piedras analiza la obra del director Michael Haneke que, de forma cinematográfica, se vale de "utilizar la imagen del sufrimiento animal como reflejo y heraldo del sufrimiento humano" (172). El maltrato animal, termina afirmando el autor, "se convierte en horrible preludio del otro" (Ídem).

Partiendo de la tesis de que los filósofos de habla española y portuguesa son invisibles, Pablo Drews elabora un mapa de los porqués y propone una "terapia argumentativa" (180) apostando por la filosofía fermentaria del gran filósofo uruguayo Carlos Vaz Ferreira. Estos porqués son estudiados y clasificados en tres grandes vicios que actuarían como freno para la visibilidad misma de la filosofía latinoamericana, a saber, "el fervor sucursalero" (181), el "afán de novedades" (182) y el "entusiasmo nacionalista” (183). A través de la filosofía de Carlos Vaz Ferreira, que aunó su esfuerzo en combatir los malos hábitos mentales y lingüísticos de estos vicios en perpetuo diálogo con la filosofía vitalista, la pragmatista y las filosofías latinoamericanas, afirma que los problemas sociales y políticos de las democracias podrían ser resueltos y tratados de una forma concreta para conseguir así un verdadero crecimiento epistémico y ontológico, tanto como una verdadera visibilidad.

Vanessa Vidal, en una apuesta novedosa derivada de su intrincado y permanente estudio de la obra de Walter Benjamin y Theodor W. Adorno, nos introduce en una de las ideas más complejas de la Modernidad: la de imagen dialéctica. Sin embargo, si bien este concepto es atribuido a Benjamin, la ensayista evidencia a través de un estudio exegético que la primera formulación publicada de esta idea pertenece a Adorno, concretamente, está elaborada en su obra Kierkegaard. Konstruktion des Ästhetischen. Vanessa Vidal lleva a cabo una exposición de las imágenes dialécticas mostrando la profunda relación entre el mito, la imagen y la dialéctica en los textos platónicos entendida por Adorno desde Kierkegaard: "El mito cambia, desarrolla una historia interna al entrar en una nueva configuración con lo conceptual y se convierte en imagen en el interior del discurso filosófico" (215). Desde este momento, mostrará la importancia de esta reflexión de Adorno sobre las imágenes dialécticas, proponiendo la necesidad de utilizarlas como el verdadero instrumento de la filosofía contemporánea.

El breve ensayo "Walter Benjamin hacia el surrealismo" de Salvador Cuenca Almenar focaliza su atención en el viraje benjaminiano del interés por la obra barroca y romántica alemana hacia la Vanguardia artística y política surrealista. Las tesis transformadoras y liberadoras del surrealismo - el goce corporal, la experiencia viva, entre otras- apoyaron su crítica al concepto de experiencia kantiano, a saber: el empobrecimiento moderno de la experiencia. De forma amena y perspicaz, Salvador Cuenca profundiza en estas tesis y cartografía el sentir intelectual del berlinés y sus influencias filosóficas y políticas. Como final abierto, el ensayista plantea una actividad teórico-práctica: mirar nuestra sociedad con los ojos críticos en momentos concretos de nuestra actualidad.

Desde la antropología política, Miquel Ángel Martínez y Josep Artés, en "Relatos salvajes, bárbaros y civilizados. La importancia de la antropología en el análisis de Deleuze y Guattari", presentan y estudian las constituciones de las diferentes formaciones del poder y el respectivo control y dominio por parte de éstas de la población en su implementación histórica. Apoyándose en el Anti-Edipo de G. Deleuze y F. Guattari, proponen una relectura de las categorías tradicionales básicas de la antropología oc- 
cidental. De este modo, el "salvaje" -o máquina territorial de las sociedades contra el Estado-, el "bárbaro" - o máquina despótica de las sociedades imperialistas- y el "civilizado" -o máquina capitalista- son presentados para comprender y entrever desde la antropología las consecuencias, dimensiones y repercusiones de las políticas ejercidas por el poder contemporáneo del sistema neoliberal.

Analizando una de las obras fundamentales de Cormac McCarthy, Meridiano de sangre, Juan David Mateu realiza una lectura antropológica extremadamente concisa y muy atenta de los personajes principales de la novela para evidenciar las figuras de la alteridad que aparecen en el "occidente salvaje". De este modo, identifica al salvaje -los indios-, al bárbaro -los mercenarios-y a los civilizados -el juez- para, desde los ojos y el relato de un niño sin nombre, hacer comprensible que la línea que diferencia a estas categorías conceptuales antropológicas no sólo no es clara, sino que es inexistente. Juan David Mateu argumenta y demuestra, siempre desde una lectura profunda del texto, cómo todos los personajes entrecruzan esas definiciones, mostrando así que todos tienen una naturaleza humana inexorablemente unida a la violencia y la destrucción. Elementos, por otra parte, que le llevan a plantear y a elaborar una enjundiosa discusión filosófica sobre la propia naturaleza humana y su carácter violento.

En "Epistemologías y política de la psiquiatría. Apuntes sobre psiquiatría crítica" Carlos García-García hace una presentación rigurosa de la creación y la historia de la psiquiatría crítica y, basándose en reflexiones aportadas por sus padres fundadores Ronald Laing, Michel Foucault, Thomas Szasz y Erving Goffman- despierta al lector la necesidad epistémica de preguntarse por la inexacta vinculación de la psiquiatría con el saber científico o -la petición de esta corriente- a las humanidades. Desde la psiquiatría crítica, defiende Carlos García-García, hay un ataque directo a la concepción mecanicista-cientificista del ser humano y una apuesta por entender al paciente como una subjetividad compleja y dinámica, apostando así por un cambio político e institucional en la disciplina de la psiquiatría.

Paolo Stellino evidencia en "Orientalismo, perspectivismo y representaciones cinematográficas de la guerra de Irak" cómo la hegemonía cultural americana es transmisora en sus producciones fílmicas de una perspectiva reduccionista sobre Oriente. ${ }^{1}$ En la línea de E. Said, Paolo Stellino desvela esta problemática a través de un análisis fílmico certero, tanto de las escenas de diversas películas como de sus diálogos. La crítica se realiza inmanentemente contra los prejuicios, la falta de reflexión que el film mismo prohíbe por su estructura cinematográfica, el reduccionismo y la flagrante eliminación de las diferentes perspectivas que no sean las "adecuadas" para los intereses culturales hegemónicos, transmitiendo así una "óptica deforme y reductiva" (371) de la realidad.

Jordi Valor, en "Retos que la verdad plantea al relativismo", sugiere un debate epistémico que afecta de lleno a la antropología cultural. El ensayo nos sitúa ante las problemáticas fundacionales del relativismo, mostrándonos cómo en función de la necesidad, valor, fuerza, exigencia o ambivalencia que se le dé al concepto de verdad, las prácticas, sobre todo en la antropología, pueden verse seriamente afectadas. Su propuesta es hacer entender que, si bien el relativista "no puede renunciar a la verdad

1 Paolo Stellino comenta que, ya en la primera imagen del film American Sniper, se deja constancia de esta relación conflictiva entre Occidente y Oriente como un "choque de civilizaciones". Paolo Stellino, "Orientalismo, perspectivismo y representaciones cinematográficas de la guerra de Irak”, en: Ibíd., pp. 366-367. 
de forma categórica", el relativista debe "desarrollar sus ideas sobre la coexistencia de una pluralidad de marcos normativos igual de valiosos" (413).

Por último, Joan B. Llinares presenta en "Notas de filosofía y antropología filosófica en las memorias de Buchenwald de Jorge Semprún" no sólo un breve y riguroso relato vital sobre el intelectual español, sino un discurso intrínseco que elabora toda la trayectoria literaria y humanista desde sus primeros años como estudiante de filosofía hasta la presentación de los temas trascendentales de los que Semprún habló, trató, investigó y sintió a lo largo de toda su vida: el mal, la libertad, la muerte y Dios. Joan B. Llinares se introduce en las problemáticas filosóficas a través de las discusiones de Semprún no sólo con la tradición más antigua, sino con la contemporánea: Kant, Schelling, Heidegger o Wittgenstein son los interlocutores de un hombre que, como el mismo Joan B. Llinares afirma en la primera página de su ensayo, no merece ser desconocido.

Antropología filosófica y literatura, por tanto, tiene, dentro de sí, no sólo un excelente ejemplo de una mirada antropológico-filosófica sobre la literatura, sino la demostración tácita e inmanente de que es en la lectura lenta y sosegada de los textos donde una persona puede encontrar el amor por un oficio crítico y una disciplina vital, personal e íntima: la reflexión sobre el "yo", el "otro" y el "nosotros". 


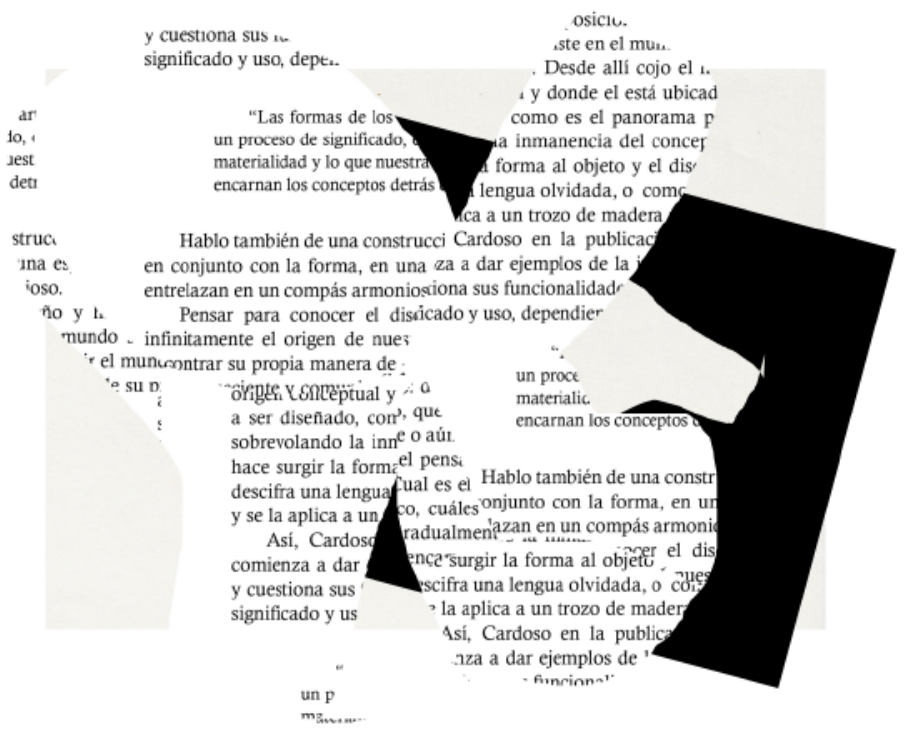

"Lo impreso exige una humildad de espíritu por cuya falta muchas de las bellas artes se tambalean ahora en experimentos de autoconciencia y sensiblería. No hay nada simple ni aburrido en lograr una página transparente. La ostentación vulgar es el doble de fácil que la disciplina".

Beatrice Warde, The Crystal Goblet, or why printings should be invisible (1930)

"El diseño que es objetivo, comprometido con el bien común, bien compuesto y delicado, constituye la base del comportamiento democrático".

Josef Müller-Brockmann, Grid and Design Philosophy (1981) 

EDITA

\section{SEyTA.}

SOCIEDAD ESPAÑLAA
DE ESTETICA Y TEORIA DE LAS ARTES

CON LA COLABORACIÓN DE

\begin{tabular}{|c|c|c|}
\hline 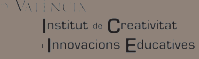 & $\begin{array}{l}\text { VNIVIRSIIN } \\
\text { II) VIIINCL Departament de Filosofia }\end{array}$ & 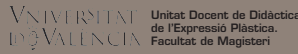 \\
\hline $\begin{array}{l}\text { ESTETICA } \\
\text { FLOSOFIA }\end{array}$ & 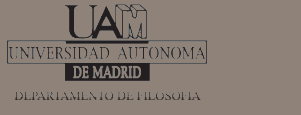 & $\begin{array}{l}\text { UAB } \\
\begin{array}{l}\text { Universitat Autònoma } \\
\text { de Barcelona }\end{array}\end{array}$ \\
\hline
\end{tabular}

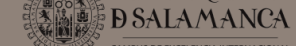

https://ojs.uv.es/index.php/LAOCOONTE/index 